\title{
Safety of endoscopic procedures after acute myocardial infarction: A systematic review
}

\author{
Marek Cena ${ }^{1 *}$, Javier Gomez ${ }^{1 *}$, Tareq Alyousef ${ }^{2}$, Richard G. Trohman ${ }^{3}$, \\ Krzysztof Pierko ${ }^{1}$, Rajender Agarwal ${ }^{1}$ \\ ${ }^{1}$ Department of Medicine, John H. Stroger Jr. Hospital of Cook County, Chicago, IL, USA \\ ${ }^{2}$ Division of Cardiology, John H. Stroger Jr. Hospital of Cook County, Chicago, IL, USA \\ ${ }^{3}$ Section of Cardiology, Rush University Medical Center, Chicago, IL, USA
}

\begin{abstract}
Background: The management of patients who develop gastrointestinal (GI) bleeding after acute myocardial infarction (MI) is difficult due to concerns about possible cardiovascular complications. Gastroenterologists are often reluctant to perform endoscopic procedures despite urgent indications. We performed a systematic review of the literature to determine the safety of endoscopic procedures after MI.
\end{abstract}

Methods: We searched MEDLINE, EMBASE and the Cochrane Central Register of Controlled trials for controlled clinical trials or case series examining the diagnostic efficacy and complications of esophagogastroduodenoscopy (EGD), colonoscopy and flexible sigmoidoscopy after MI. Title and abstract screening was followed by full-text review with subsequent data extraction of included studies.

Results: A total of seven studies met inclusion criteria. Four studies evaluated safety and efficacy of EGD after MI. The reported complication rate ranged between 1-8\%, with a large predominance of minor complications. We found one study addressing safety of flexible sigmoidoscopy that reported minor complications in two patients. We also identified one study addressing the safety of colonoscopy after MI, which showed a complication rate of 9\%. Most of these complications were minor. A decision analysis was also included in this review.

Conclusions: Our review demonstrated that endoscopic procedures are safe and beneficial in stable patients with GI bleeding after recent MI and should be performed without a requisite delay. Unstable patients should undergo endoscopic procedures only in the intensive care setting, after stabilization and with close monitoring. (Cardiol J 2012; 19, 5: 447-452)

Key words: endoscopy, myocardial infarction, systematic review

\section{Introduction}

Patients with myocardial infarction (MI) may, in theory, be more susceptible to cardiovascular complications caused by endoscopic procedures.
Management of patients who develop gastrointestinal (GI) bleeding after acute MI, or patients with evidence of active GI bleeding at the time of MI is challenging. Despite urgent indications, gastroenterologists may be reluctant to perform endosco-

\footnotetext{
Address for correspondence: Rajender Agarwal, MD, MPH, Department of Medicine, Stroger Hospital of Cook County, 1901 W Harrison Street, Chicago, IL 60612, USA, tel: 215-873-1820, e-mail: rajender.agarwal@gmail.com

*Marek Cena and Javier Gomez contributed equally to the manuscript and should be treated as co-first authors.

Received: 15.05.2012

Accepted: 30.06.2012
} 
Table 1. Sample search strategy for OVID MEDLINE.

Phase 1: Search terms for myocardial infarction
1. exp Myocardial Infarction
2. (myocardial adj infarction).mp.
3. exp Acute Coronary Syndrome
4. or/1-3
Phase 2: Search terms for endoscopy
5. exp Endoscopy
6. exp Endoscopy, Gastrointestinal
or exp Endoscopy, Digestive System
7. exp Esophagoscopy
8. exp Gastroscopy
9. exp Duodenoscopy
10. exp Colonoscopy
11. (EGD or endoscopy).mp.
12. or/5-11
Phase $3:$ Combining the searches and
restricting to English
13. 4 and 12
14. limit 13 to English language

pic procedures in patients with acute or recent MI. In the absence of diagnostic and therapeutic endoscopy, standard percutaneous coronary intervention (PCI) protocols, including anticoagulation or fibrinolytic therapy are frequently withheld resulting in poorer outcomes.

Currently, there are no guidelines to address these difficult issues. We performed a systematic review of the safety and efficacy of endoscopic procedures in the setting of acute or recent $\mathrm{MI}$ in order to clarify the risk/benefit ratio and provide preliminary recommendations.

\section{Methods}

\section{Study selection}

We searched MEDLINE (1950 to March 2012), EMBASE (1980 to March 2012) and the Cochrane Central Register of Controlled Trials (inception to March 2012) using keywords and/or medical subject headings (MeSH) for MI and endoscopic procedures. The detailed search strategy can be found in Table 1. We screened the titles and abstracts of references identified in our search and those meeting our inclusion criteria were retrieved for full-text review.

Two investigators (MC and JG) independently screened titles, abstract and full-texts. To be included, a study had to be a clinical trial or case series (with predefined inclusion study sample size above
20 patients), examining the diagnostic efficacy and complications of esophagogastroduodenoscopy (EGD), colonoscopy or flexible sigmoidoscopy within 30 days after MI. References not published in English were excluded.

\section{Data extraction}

We extracted data on the study design, patient population, endoscopic procedure used, and the size of the study sample. The primary outcome of interest was development of cardiovascular complications during or after the endoscopic procedures. In addition, we examined the efficacy of the endoscopic procedures in terms of diagnostic yield and impact on management.

\section{Results}

\section{Study flow and characteristics}

Our literature search yielded 420 references of which 25 full text articles were retrieved. Seven studies [1-7] met our predefined inclusion criteria.

Study characteristics are shown in Table 2. No randomized controlled trials were identified. Three studies were controlled clinical trials $[1,3,4]$, three studies did not have control groups $[2,5,6]$ and one was a decision analysis [7]. The seven studies included 1081 patients. All study participants had a diagnosis of GI bleeding (upper or lower) as the indication for endoscopy. Five studies included patients undergoing EGD [3-7], one evaluated flexible sigmoidoscopy [2] and one evaluated colonoscopy [1].

\section{Outcomes}

Flexible sigmoidoscopy. Cappell [2] evaluated the risks and benefits of flexible sigmoidoscopy after MI. This study demonstrated a diagnostic yield of 37\%. Therapeutic benefit was achieved in $9 \%$ of patients. Two patients had complications, of which one was considered minor (asymptomatic transient bradycardia) and the other one was an MI.

Colonoscopy. A study by the same authors evaluated the safety and efficacy of colonoscopy after MI in a controlled trial, the control group included patients with GI bleed without history of MI. The diagnostic yield was similar, $46 \%$ in the MI group and $40 \%$ in the control group $(\mathrm{p}=0.47)$. There was a higher complication rate of $9 \%(9 \mathrm{pa}-$ tients) in the MI group vs. $1 \%$ (1 patient) in the control group $(\mathrm{p}<0.03)$. However, 8 of the 9 patients had minor complications (transient hypotension in 7 patients and transient bradycardia in 1 patient) which resolved upon conclusion of the procedure. One major complication was reported (death $14 \mathrm{~h}$ 
Table 2. Study characteristics.

\begin{tabular}{|c|c|c|c|c|c|c|}
\hline $\begin{array}{l}\text { Author, year } \\
\text { (reference) }\end{array}$ & $\begin{array}{l}\text { Study } \\
\text { design }\end{array}$ & $\begin{array}{c}\text { Study } \\
\text { objective }\end{array}$ & Population & $\mathbf{N}$ & Intervention & Control \\
\hline \multicolumn{7}{|c|}{ Flexible sigmoidoscopy } \\
\hline Cappell, 2004 & Uncontrolled & $\begin{array}{l}\text { Risk vs. benefit } \\
\text { of flexible } \\
\text { sigmoidoscopy } \\
\text { after MI }\end{array}$ & $\begin{array}{c}\text { Patients } 30 \text { day } \\
\text { after } \mathrm{Ml}\end{array}$ & 78 & $\begin{array}{l}\text { Flexible } \\
\text { sigmoido- } \\
\text { scopy }\end{array}$ & None \\
\hline \multicolumn{7}{|l|}{ Colonoscopy } \\
\hline Cappell, 2004 & Controlled & $\begin{array}{l}\text { Risk vs. benefit } \\
\text { of colonoscopy } \\
\text { soon after Ml }\end{array}$ & $\begin{array}{c}\text { Patients } 30 \text { days } \\
\text { after } \mathrm{Ml}\end{array}$ & 200 & $\begin{array}{l}\text { Colono- } \\
\text { scopy }\end{array}$ & $\begin{array}{l}\text { Patients } \\
\text { having } \\
\text { colonoscopy } \\
\text { without MI }\end{array}$ \\
\hline \multicolumn{7}{|l|}{ EGD } \\
\hline Cappell, 1999 & Controlled & $\begin{array}{l}\text { Establish safety } \\
\text { and efficacy } \\
\text { of EGD after MI }\end{array}$ & $\begin{array}{c}\text { Patients } \\
\text { undergoing EGD } \\
\text { within } 30 \text { days } \\
\text { after } \mathrm{Ml}\end{array}$ & 400 & EGD & $\begin{array}{c}\text { Patients } \\
\text { having } \mathrm{EGD} \\
\text { without } \mathrm{Ml} \\
\text { in last } 6 \text { months }\end{array}$ \\
\hline Lin, 2006 & Controlled & $\begin{array}{c}\text { Predictors } \\
\text { of endoscopic } \\
\text { therapy in patients } \\
\text { with UGIB and MI }\end{array}$ & $\begin{array}{l}\text { Patients with } \\
\text { UGIB and MI } \\
\text { (7 days) }\end{array}$ & 183 & $\begin{array}{l}\text { MI after } \\
\text { UGIB }\end{array}$ & UGIB after MI \\
\hline Mumtaz, 2007 & Uncontrolled & $\begin{array}{l}\text { Safety and utility } \\
\text { of EGD in post-MI } \\
\text { patients }\end{array}$ & $\begin{array}{l}\text { Patients } \\
\text { undergoing } \\
\text { EGD within } \\
4 \text { weeks of } \mathrm{MI}\end{array}$ & 85 & EGD & None \\
\hline Spier, 2007 & Uncontrolled & $\begin{array}{l}\text { Safety and efficacy } \\
\text { of EGD after MI }\end{array}$ & $\begin{array}{c}\text { Patients } \\
\text { undergoing } \\
\text { EGD within } \\
30 \text { days after MI }\end{array}$ & 135 & EGD & None \\
\hline \multicolumn{7}{|l|}{ Decision analysis } \\
\hline Yachimski, 2008 & $\begin{array}{l}\text { Decision } \\
\text { analysis }\end{array}$ & $\begin{array}{l}\text { Safety of EGD } \\
\text { prior to CATH in } \\
\text { patients with MI }\end{array}$ & $\begin{array}{l}\text { Patients with } \\
\text { UGIB and MI }\end{array}$ & $\begin{array}{l}10,000 \\
\text { hypo- } \\
\text { thetical }\end{array}$ & $\begin{array}{l}\text { EGD } \\
\text { before } \\
\text { CATH }\end{array}$ & $\begin{array}{l}\text { Direct CATH } \\
\text { (no EGD) }\end{array}$ \\
\hline
\end{tabular}

CATH — cardiac catheterization; EGD — esophagogastroduodenoscopy; MI - myocardial infarction; UGIB — upper gastrointestinal bleeding

after colonoscopy) and was not believed by the investigators to be related to the procedure [1].

Esophagogastroduodenoscopy. Four studies evaluated the safety and efficacy of EGD after MI [3-6]. Mumtaz et al. [5] found a diagnostic yield of $88 \%$. A therapeutic intervention was performed in $30 \%$ of patients at the time of the procedure. The complication rate was $8 \%$ (7 patients), which included hypotension (3 patients), bradycardia ( 2 patients) and hypoxia ( 2 patients). There were no procedure related deaths in the study.

Cappell and Iacovone [3] studied EGD after MI in a controlled study; the control group had similar indications for EGD without MI within 6 months. The diagnostic yield was $85 \%$ in the MI group and $83 \%$ in the control group $(\mathrm{p}=0.79)$. There was a therapeutic benefit in $6 \%$ of the MI group patients. The complication rate was $1.5 \%$ (3 patients) in the control group and $7.5 \%$ (15 patients) in the MI group. Of these, complications in 13 patients were considered mild and included 11 instances of transient hypotension and 2 of transient hypoxia. The other 2 complications where major and included 1 fatal ventricular tachycardia and 1 near respiratory arrest.

Spier et al. [6] demonstrated that the diagnostic yield of EGD was $68.4 \%$ associated with a therapeutic benefit in $19.4 \%$ of patients. The complication rate was $1.5 \%$ (2 patients who experienced hypotension, bradycardia and hypoxia). In a subgroup analysis, there was no increased risk of complications in patients with ST elevation MI $(p=1.0)$, patients with depressed left ventricular function $(\mathrm{p}=0.41)$ or those with elevated troponin levels $(p=1.0)$. Six patients had all three risk factors and did not experience any complications.

Lin et al. [4] evaluated predictors of endoscopic therapy in patients with both upper GI bleed and MI. In this study, groups were divided into patients 
presenting with upper GI bleed who then developed an MI (GI bleed group) and patients presenting with MI who subsequently developed upper GI bleed (MI group). The diagnostic yield of EGD in both groups was similar - 78\% in the GI bleed group and $80 \%$ in the MI group ( $\mathrm{p}=\mathrm{NS})$. The therapeutic efficacy of EGD was $41 \%$ in the GI bleed group and $17 \%$ in the MI group $(\mathrm{p}<0.01)$. Only severe complication rates were reported and were $1 \%$ in each group.

Decision analysis. Yachimski et al. [7] created a decision analytic model from a hypothetical cohort of 10,000 patients. Using decision analysis, patients with upper gastrointestinal bleeding (UGIB) and acute MI were assigned to one of two strategies: (1) EGD prior to cardiac catheterization (EGD strategy) and (2) cardiac catheterization without EGD (CATH strategy). In patients with overt UGIB, the EGD strategy resulted in 97 deaths per 10,000 patients, compared with 600 deaths per 10,000 patients with the CATH strategy. The EGD strategy also resulted in fewer non-fatal complications (1,271 vs. 6,000 per 10,000 patients). Conversely, in patients with occult GI bleeding, the EGD strategy resulted in more deaths (59 vs. 16 per 10,000 patients) and more non-fatal complications (888 vs. 160 per 10,000 patients) than the CATH strategy. Patients were stratified by cardiac risk categories based on ejection fraction (normal, moderately depressed or severely depressed), the degree of troponin elevation and STEMI vs. NSTEMI. There was no statistically significant association of any of these categories with endoscopy-related complications.

\section{Discussion}

The mortality from acute coronary syndromes has significantly decreased in the last few decades [8-10]. Most of the improvement in the 30-day post MI mortality comes from increased use of fibrinolytic therapy and PCI. Anti-platelet agents (such as aspirin, clopidogrel, prasugrel), glycoprotein IIb/IIIa inhibitors, as well as anticoagulation with unfractionated or low molecular weight heparin play an important role in peri- and post-PCI therapy. The use of anti-platelet agents and heparin carries an increased risk of bleeding. The majority of bleeding occurs at the site of vascular access [11] but gastrointestinal bleeding also takes place. Approximately $2 \%$ of patients undergoing PCI experience GI bleeding [11, 12]. GI bleeding following PCI prolongs hospital stay and carries increased mortality risk [12].

Endoscopy plays a major role in the diagnosis and therapy of GI bleeding. Endoscopic procedures, in general, are considered to be very safe and well tolerated with a very low complication rate in general population [13-15]. Mild complications in the form of alterations in heart rate, blood pressure, oxygen saturation, as well as ST-segment changes are well known and documented in the literature [16-25]. Acute and severe cardiovascular complications in the form of MI, vasovagal reaction, arrhythmias, and congestive heart failure occur very infrequently during gastrointestinal endoscopy with an overall incidence of $0.14 \%$ [26]. Serious complications occur exclusively in the setting of known underlying heart disease. In patients with severe coronary artery disease peri-procedural ischemia occurs in $16 \%$ of patients [27].

To our knowledge, this is the first systematic review on the safety of endoscopic procedures after MI. Our results demonstrated that EGD is safe and beneficial within one month after $\mathrm{MI}$ in relatively stable patients with significant bleeding and should be performed in these patients without unnecessary delay. The complication rate of endoscopic procedures after MI ranged from 1-9\% with $81 \%$ being considered minor by the original investigators. All endoscopic complications in patients with MI were cardiopulmonary. The predominance of cardiopulmonary complications, as suggested by Cappell and Iacovone [3], probably occurs because MI decreases cardiopulmonary reserve but is not likely to affect the risk of other complications, such as gastrointestinal perforation or hemorrhage. Cardiopulmonary complications may also depend more on general clinical status, whereas other complications are more affected by the skill of the operator and the patient's anatomy [28].

The timing of endoscopy in relation to $\mathrm{MI}$ is likely important in terms of risk. Depending on the clinical scenario (e.g., hemodynamically significant vs. non-hypotensive GI bleeding), it may be reasonable to wait upwards of a week after MI before performing the endoscopy. In the study by Spier et al. [6], the complication rate of endoscopy performed on hospital day 0 vs. $>24 \mathrm{~h}$ after MI was significantly higher $(11.8 \%$ vs. $0 \%$, respectively, $\mathrm{p}=0.02)$. The overall 30 day risk was low. Unfortunately, sicker patients are likely to require endoscopy sooner rather than later.

The general consensus on transfusion strategy in patients with coronary artery disease has been to maintain the hemoglobin level $>10 \mathrm{~g}$. A recently published randomized controlled trial was the first to compare transfusion strategies in patients with acute MI. This trial showed that a transfusion threshold of hemoglobin $<10 \mathrm{~g}$ was associated with a significantly increased risk of death, recurrent MI 
or new or worsening congestive heart failure compared with a transfusion threshold of hemoglobin $<8 \mathrm{~g}$ [29]. Thus, the benefits of prompt transfusion and urgent diagnostic/therapeutic intervention should be carefully weighed against the risks.

Patients with MI who develop GI bleeding are often on antiplatelet agents for primary or secondary prophylaxis. Current guidelines state that the decision to discontinue antiplatelet agents in the setting of an acute GI bleed should be made on an individual basis, and these drugs should be restarted as soon as the risk for cardiac events is thought to outweigh the risk of bleeding [30].

A review of the safety of endoscopic procedures such endoscopic retrograde cholangiopancreatography (ERCP) and endoscopic ultrasound was beyond the scope of our review due to their elective nature and available alternatives which may be less invasive and risky. However, it has been shown in the literature that ERCP also carries acceptable risks when performed soon after acute coronary syndrome [31].

Our review is limited by the small number of included studies. We found no randomized controlled studies and the numbers of patients in the included studies are small. Future research should focus on larger cohort studies and possibly prospective, randomized controlled trials, although the latter may be difficult to perform.

\section{Conclusions}

Our review suggests that relatively stable patients with significant bleeding or other strong indications for endoscopy should undergo the procedure even in the event of a recent or active MI. Such patients should have the procedure performed with electrocardiographic, blood pressure, and pulseoximetry monitoring. Clinically unstable patients with hypoxia, hypotension, life-threatening arrhythmias, or angina are at an increased risk of cardiovascular complications from endoscopic procedures. Such patients might also undergo the procedure in an intensive care setting and after clinical stabilization. This may require transfusion of red blood cells in the case of severe blood loss, treatment of underlying cardiac conditions (such as decompensated heart failure, arrythmias etc.) or endotracheal intubation with mechanical ventilation [3].

Conflict of interest: none declared

\section{References}

1. Cappell MS. Safety and efficacy of colonoscopy after myocardial infarction: An analysis of 100 study patients and 100 control patients at two tertiary cardiac referral hospitals. Gastrointest Endosc, 2004; 60: 901-909.

2. Cappell MS. Risks versus benefits of flexible sigmoidoscopy after myocardial infarction: An analysis of 78 patients at three medical centers. Am J Med, 2004; 116: 707-710.

3. Cappell MS, Iacovone FM, Jr. Safety and efficacy of esophagogastroduodenoscopy after myocardial infarction. Am J Med, 1999; 106: 29-35.

4. Lin S, Konstance R, Jollis J et al. The utility of upper endoscopy in patients with concomitant upper gastrointestinal bleeding and acute myocardial infarction. Digestive Diseases Scien, 2006; 51: 2377-2383.

5. Mumtaz K, Ismail FW, Jafri W et al. Safety and utility of oesophago-gastro-duodenoscopy in acute myocardial infarction. Eur J Gastroenterol Hepatol, 2008; 20: 51-55.

6. Spier BJ, Said A, Moncher K et al. Safety of endoscopy after myocardial infarction based on cardiovascular risk categories: A retrospective analysis of 135 patients at a tertiary referral medical center. J Clin Gastroenterol, 2007; 41: 462-467.

7. Yachimski P, Hur C. Upper endoscopy in patients with acute myocardial infarction and upper gastrointestinal bleeding: Results of a decision analysis. Digestive Diseases Scien, 2009; 54: 701-711.

8. Gibson CM, Pride YB, Frederick PD et al. Trends in reperfusion strategies, door-to-needle and door-to-balloon times, and in-hospital mortality among patients with ST-segment elevation myocardial infarction enrolled in the National Registry of Myocardial Infarction from 1990 to 2006. Am Heart J, 2008; 156: 1035-1044.

9. Krumholz HM, Wang Y, Chen J et al. Reduction in acute myocardial infarction mortality in the United States: Risk-standardized mortality rates from 1995-2006. JAMA, 2009; 302: 767-773.

10. Rogers WJ, Frederick PD, Stoehr E et al. Trends in presenting characteristics and hospital mortality among patients with ST elevation and non-ST elevation myocardial infarction in the National Registry of Myocardial Infarction from 1990 to 2006. Am Heart J, 2008; 156: 1026-1034.

11. Kinnaird TD, Stabile E, Mintz GS et al. Incidence, predictors, and prognostic implications of bleeding and blood transfusion following percutaneous coronary interventions. Am J Cardiol, 2003; 92: 930-935.

12. Abbas $\mathrm{AE}$, Brodie $\mathrm{B}$, Dixon $\mathrm{S}$ et al. Incidence and prognostic impact of gastrointestinal bleeding after percutaneous coronary intervention for acute myocardial infarction. Am J Cardio, 2005; 96: 173-176.

13. Hart R, Classen M. Complications of diagnostic gastrointestinal endoscopy. Endoscopy, 1990; 22: 229-233.

14. Arrowsmith JB, Gerstman BB, Fleischer DE et al. Results from the American Society for Gastrointestinal Endoscopy/U.S. Food and Drug Administration collaborative study on complication rates and drug use during gastrointestinal endoscopy. Gastrointest Endosc, 1991; 37: 421-427.

15. Newcomer MK, Brazer SR. Complications of upper gastrointestinal endoscopy and their management. Gastrointest Endosc Clin N Am, 1994; 4: 551-570. 
16. Fujita R, Kumura F. Arrythmias and ischemic changes of the heart induced by gastric endoscopic procedures. Am J Gastroenterol, 1975; 64: 44-48.

17. Alam M, Schuman BM, Duvernoy WF et al. Continuous electrocardiographic monitoring during colonoscopy. Gastrointest Endosc, 1976; 22: 203-205.

18. Levy N, Abinader E. Continuous electrocardiographic monitoring with Holter electrocardiocorder throughout all stages of gastroscopy. Am J Dig Dis, 1977; 22: 1091-1096.

19. Bough EW, Meyers S. Cardiovascular responses to upper gastrointestinal endoscopy. Am J Gastroenterol, 1978; 69: 655-661.

20. Lieberman DA, Wuerker CK, Katon RM. Cardiopulmonary risk of esophagogastroduodenoscopy. Role of endoscope diameter and systemic sedation. Gastroenterology, 1985; 88: 468-472.

21. Mathew PK, Ona FV, Damevski K et al. Arrhythmias during upper gastrointestinal endoscopy. Angiology, 1979; 30: 834-840.

22. Segawa K, Nakazawa S, Yamao K et al. Cardiac response to upper gastrointestinal endoscopy. Am J Gastroenterol, 1989; 84: 13-16.

23. Woods SD, Chung SC, Leung JW et al. Hypoxia and tachycardia during endoscopic retrograde cholangiopancreatography: Detection by pulse oximetry. Gastrointest Endosc, 1989; 35: 523-525.

24. Kinoshita $Y$, Ishido S, Nishiyama K et al. Arterial oxygen saturation, blood pressure, and pulse rate during upper gastrointesti- nal endoscopy: Influence of sedation and age. J Clin Gastroenterol, 1991; 13: 656-660.

25. Fennerty MB, Earnest DL, Hudson PB et al. Physiologic changes during colonoscopy. Gastrointest Endosc, 1990; 36: 22-25.

26. Lee JG, Leung JW, Cotton PB. Acute cardiovascular complications of endoscopy: Prevalence and clinical characteristics. Dig Dis, 1995; 13: 130-135.

27. Lee JG, Krucoff MW, Brazer SR. Periprocedural myocardial ischemia in patients with severe symptomatic coronary artery disease undergoing endoscopy: Prevalence and risk factors. Am J Med, 1995; 99: 270-275.

28. Quine MA, Bell GD, McCloy RF, Matthews HR. Prospective audit of perforation rates following upper gastrointestinal endoscopy in two regions of England. Br J Surg, 1995; 82: 530-533

29. Cooper HA, Rao SV, Greenberg, MD et al. Conservative versus liberal red cell transfusion in acute myocardial infarction (the CRIT randomized pilot study). Am J Cardiol, 2011; 108: 1108-1111.

30. Barkun AN, Bardou M, Kulpers EJ et al. International consensus recommendations on the management of patients with non-variceal upper gastrointestinal bleeding. Ann Intern Med, 2010; 152: 101-113

31. Nojkov B, Cappell MS. Safety and efficacy of ERCP after recent myocardial infarction or unstable angina. Gastrointest Endosc, 2010; 72: 870-880. 